\title{
Market-friendly agricultural development - implications for seeds and smallholders in Sub-Saharan Africa
}

ASBTRACT: Across Sub-Saharan Africa efforts to produce and supply the agricultural technologies that are expected to intensify smallholder agricultural production are strongly market-oriented. Here, the case of maize seeds in Malawi provides new insights into some of the implications of this orientation. Malawi presents a context where market liberalisation coupled with a national input subsidy programme has led to the growth of corporate power within the formal maize seed system and a strong reliance upon commercial providers to breed, multiply and diffuse new cultivars. At both the local and national levels, facets of this market-orientation mean that poverty reduction and climate change adaptation goals may not be met. In order to address these potential shortcomings multiple measures are required. Institutions are needed to oversee the co-ordination of appropriate breeding and marketing efforts by corporate actors within the formal seed system; research programmes are required which can enhance understandings of genetic evolution within farmersaved varieties and its implications for climate resilience, and policies must be carefully implemented which can support market participation by the poorest.

Keywords: agricultural technology, climate change adaptation, poverty reduction, seed systems Transactional technology transfer, climate change adaptation and poverty reduction

Aspirations for developing smallholder agriculture in Sub-Saharan Africa (SSA) have for some time been driven by the need to address the high levels of poverty and food insecurity which characterise livelihoods of large sections of the continent's population. Today, climate change adds another dimension to these concerns, introducing questions about agricultural adaptation to current and future climate variability and change. For decades, agricultural development objectives in the region have been shaped by the assumption that promoting the use of modern cultivars for important staple crops such as rice and maize alongside inputs such as inorganic fertiliser and pesticides (in 
pursuit of an Asian-style 'green revolution') will lead to productivity transformations which will achieve food security and launch broader economic growth (Woodhouse 1989; Diao et al. 2010). However, it is notable that attempts to launch Africa's green revolution have met with much less success than originally hoped for, and contemporary yields across the continent remain far lower than those achieved elsewhere (Cairns et al. 2013). Despite this, the overarching developmental goals for smallholder agriculture have remained the same, and, whilst conceptual frameworks for understanding agricultural change have evolved from "a neat, transactional concept of technology adoption" (Glover et al. 2016, p. 4; Rogers 2003) to embrace a more complex systems-oriented perspective (The World Bank 2012), the strategies pursued continue to focus on promoting 'superior' forms of agricultural technology via market exchange. This article argues that these strategies over-estimate the financial capacity of many smallholders, under-estimate the contemporary importance of informal seed systems and farmer seed-saving within production activities, and rely too heavily on business actors to incorporate public interest goals into their seed provision activities.

Increasing corporate dominance within Malawi's formal maize seed sector

In the case of Malawi, where maize is the primary staple food, there has been an overarching focus on the promotion of hybrid maize cultivars since independence. During the 'life presidency' of Hastings Banda, this objective was overseen by government arms such as the parastatal maize marketing board, ADMARC. But since 2002 market liberalisation induced by structural adjustment conditionality has coincided with a targeted national inputs subsidy scheme, which has at times been (prematurely) credited with transforming Malawi into a food secure nation and a net exporter of maize (Denning et al. 2009). Today, the programme is regarded with less aplomb as recognition has built of the degree to which its successes are contingent upon favourable seasonal rainfall, which is notably unreliable in Malawi (FAO 2017). Nonetheless, the subsidy scheme's financial injection to the newly liberalised agricultural inputs market, equivalent to an average of $9 \%$ of the Government 
of Malawi's total national spend from 2006-2013 (FAO 2014), has engendered a mushrooming of corporate power within the formal seed system. Consequently, national and international commercial brands now dominate decision-making about which cultivars to provide, and where. This has several important implications for the goals of poverty reduction and climate change adaptation.

At the national level, despite the increasing market participation of a growing range of commercial seed brands, corporate dominance means that cultivar provision to smallholders has tended to be narrowly determined by commercial interests (Chinsinga 2011). While modern maize cultivars can be either improved open-pollinated cultivars (OPVs) (which can be saved on-farm for three years before stock must be renewed) or hybrid cultivars (which are high-yielding but must be repurchased annually) there are clear commercial advantages to marketing the latter, and unsurprisingly these have been found to dominate marketed supplies to smallholders (Sutcliffe et al., 2016). Furthermore, because the maize breeding activities of the major seed companies operating in Malawi take place elsewhere on the continent, far from local contextual specificities, commercially available cultivars have been found to poorly reflect smallholder taste and processing preferences (Lunduka et al. 2012; Sutcliffe 2014), and may not be as well-suited to production environments as if they had been bred within-country. Looking to the future, breeders are reported not to be undertaking pre-emptive selections in preparation for the conditions that will likely prevail under climate change (Sutcliffe, 2014). In particular, breeding for tolerance to higher temperatures (which climate projections indicate will be important for productivity in future climates) has been something of a blind-spot for both public and private breeders alike (Challinor et al. 2016). Instead, drought has been and remains a key focus for many involved in efforts to breed new maize cultivars, as illustrated by international public good efforts like Drought Tolerant Maize for Africa (DTMA) and Water Efficient Maize for Africa (WEMA) initiatives. However, in contrast with the nuanced understandings of drought tolerance displayed by national and international public seed breeders, managers of private seed companies have been found to conflate drought tolerance with the 
capacity to escape drought that is conferred by early maturity (Sutcliffe et al., 2016). Like hybrids, early-maturing cultivars are also relatively more attractive to commercial players since they can produce a yield across a wider range of environments than late-maturing cultivars (which are only suitable in locations with longer rainy season duration). Producing more of one cultivar type with a greater marketable range again constitutes a sound commercial strategy since it facilitates an economy of scale at the seed-bulking stage and requires less complicated distribution arrangements. However, early maturing cultivars naturally yield less, achieving less vegetative development before seeds are produced, meaning that corporate over-provision of short season cultivars forecloses the option of achieving the potentially higher yields that local rainfall characteristics may permit in some areas with slower-maturing cultivars. Under the higher temperatures that will certainly be experienced as climate change progresses (which will mean maturity is reached even sooner), shorter season cultivar yields will be further reduced (Challinor et al. 2016). Whilst breeding efforts driven by non-commercial initiatives (such as DTMA) are more likely to breed maize cultivars designed to complement smallholder adoption capacities and build longer term resilience, due to market liberalisation these initiatives are now entirely dependent on commercial seed companies to multiply and market their cultivars. This means that the afore-mentioned commercial considerations also determine the availability (or lack thereof) of these 'public good' cultivars, because short-term profitability trumps other factors for corporate actors (Sutcliffe et al., 2016). At the local level the commodification of maize seeds and marketization of the formal seed system constitutes a profound shift from the traditional patterns of access which continue to characterise the informal system. Smallholder access to modern cultivars is now determined by financial capacity, whereas seed of traditional (or local) cultivars were (and still are, although they are now less prominent within household cultivar portfolios) saved on-farm or accessed at no or very low cost from friends, neighbours and relatives. Access to recommended varieties today is thus characterised by inequalities according to household wealth and location. The promotion of modern cultivars via subsidies, extension and marketing activities has been accompanied by a significant decline in local 
knowledge about the cultivars being grown on farm. As such smallholders have been found to possess poor knowledge of the names and traits of commercial cultivars, and poor understanding of whether or not the cultivars they grow are OPV or hybrid (and thus whether seed should or should not be saved) (Sutcliffe, 2014). This decline in local agro-ecological knowledge brought about by the 'industrialisation' of seed systems has been termed 'agricultural deskilling' (Kumbamu \& Stone 2007). It is concomitant with a loss of 'seed sovereignty' (Bezner Kerr 2013) over germplasm because high levels of out-crossing in wind-pollinated crops such as maize mean that gene-flow from modern hybrids will be altering genotype and trait expression within traditional landraces, (which farmer selection practices over generations have adapted to local processing and consumption preferences and environmental conditions). As a departure from the open-pollinated tradition, wherein seed could be saved from all the cultivars grown on farm, the predominant market provision of hybrid cultivars rests on an assumption that smallholders will now repeat maize purchases annually, accompanied by the belief that the informal maize seed system has been superceded and is now in decline. However, research has shown that informal seed systems remain incredibly important for seed access by smallholders across Africa (McGuire \& Sperling 2016), and in Malawi high proportions of households continue to save seeds from their harvest for the following season regardless of whether they have grown hybrids or OPVs (Sutcliffe, 2014). For poorer smallholders who cannot participate in market exchanges, reliance on the informal system continues in the form of dependence on access to recycled hybrid (F2) maize seeds donated by wealthier households. Understanding of the implications of the high use-levels of recycled hybrid seed in terms of overall yield, yield stability, and susceptibility to environmental stress remains poor and research is needed in this area.

Supporting seed systems to enhance climate change adaptation and poverty reduction

This is a necessarily brief snapshot of some of the incongruities in and between Malawi's formal and informal seed systems which affect smallholder maize production and create barriers to realising 
effective climate change adaptation and poverty reduction. The factors in Malawi that have led to the growth of corporate dominance in the seed sector (which include subsidy provision, liberalisation and the market-friendly neoliberal persuasions of international donors), are replicated in agricultural development trajectories across SSA, making it likely that the issues discussed here will be important considerations for initiatives designed to support smallholder agriculture elsewhere. The market-friendly approach supports the development of seed systems which are focussed on short-term profit and oriented towards serving wealthier smallholders. To support the longer term goal of building resilience within smallholder production systems, this overriding market focus needs to be tempered with measures that make up for the likelihood that benefits will be missed by the poorest smallholders who struggle to engage in market exchanges and for the fact that corporate interests determine different cultivar provision objectives from those of the public sector. For maize seed in Malawi such measures include scaling up (and increasing governmental support for) the social cash transfer programme, investing in research to better understand the implications of hybrid recycling, and developing institutions that can more effectively oversee corporate breeding, multiplication and distribution of maize seed.

\section{REFERENCES}

Bezner Kerr, R., 2013. Seed struggles and food sovereignty in northern Malawi. Journal of Peasant Studies, 40(5), pp.867-897.

Cairns, J.E. et al., 2013. Adapting maize production to climate change in sub-Saharan Africa. Food Security, 5(3), pp.345-360.

Challinor, A.J. et al., 2016. Current warming will reduce yields unless maize breeding and seed systems adapt immediately. Nature Climate Change, 6(10), pp.954-958.

Chinsinga, B., 2011. Seeds and Subsidies: The Political Economy of Input Programmes in Malawi. Ids Bulletin-Institute of Development Studies, 42(4), pp.59-68. 
Denning, G. et al., 2009. Input Subsidies to Improve Smallholder Maize Productivity in Malawi: Toward an African Green Revolution. Plos Biology, 7(1), pp.2-10.

Diao, X., Hazell, P. \& Thurlow, J., 2010. The Role of Agriculture in African Development. World Development, 38(10), pp.1375-1383.

FAO, 2014. Analysis of public expenditure in support of food and agriculture in Malawi 2006 - 2013,

FAO, 2017. Regional Overview of Food Security and Nutrition in Africa 2016. The challenges of building resilience to shocks and stresses.

Glover, D., Sumberg, J. \& Andersson, J.A., 2016. The adoption problem; or why we still understand so little about technological change in African agriculture. Outlook on Agriculture, 45(1), pp.3-6.

Kumbamu, A. \& Stone, G.D., 2007. Beyond Agricultural Deskilling and the Spread of Genetically Modified Cotton in Warangal. Current Anthropology, 48(6), pp.891-893.

Lunduka, R., Fisher, M. \& Snapp, S., 2012. Could farmer interest in a diversity of seed attributes explain adoption plateaus for modern maize varieties in Malawi? Food Policy, 37(5), pp.504510.

McGuire, S. \& Sperling, L., 2016. Seed systems smallholder farmers use. Food Security, 8(1), pp.179195.

Rogers, E.M., 2003. Diffusion of Innovations. Fifth Edition, Free Press, New York, London, Toronto, Sydney.

Sutcliffe, C., 2014. Adoption of improved maize cultivars for climate vulnerability reduction in Malawi. PhD thesis, University of Leeds.

Sutcliffe, C., Dougill, A.J. \& Quinn, C.H., 2016. Evidence and perceptions of rainfall change in Malawi: Do maize cultivar choices enhance climate change adaptation in sub-Saharan Africa? Regional Environmental Change, 16(4), pp.1215-1224. 
The World Bank, 2012. Agricultural Innovation Systems: An Investment Sourcebook, The World Bank, Washington DC.

Woodhouse, P., 1989. From green revolution to food security in sub-Saharan Africa Issues in research and technology development. Food Policy, 14(1), pp.7-12. 